\title{
Bismuth subsalicylate in the prevention of colonization of infant mice with Campylobacter jejuni
}

\author{
M.-L. HÄNNINEN \\ College of Veterinary Medicine, Department of Food and Environmental Hygiene, \\ P.O. Box 6, SF-00581 Helsinki, Finland
}

(Accepted 5 December 1989)

\section{SUMMARY}

Infant mice were used for the evaluation of the efficacy of bismuth subsalicylate (BSS) in the prevention of the growth of Campylobacter jejuni in the intestine. The $\mathrm{MIC}_{90}$ of ten $C$. jejuni strains was $900 \mu \mathrm{g} / \mathrm{ml}$. Of three dosage regimens tested, continuous treatment before and after the bacterial challenge, mimicking the way BSS is used in the prevention of traveller's diarrhoea, was the most effective. Growth inhibition was dose dependent; the high dose of $2000 \mu \mathrm{g}$ per day was more effective than $300 \mu \mathrm{g}$ per day. After cessation of treatment, campylobacter counts increased to the same level as in the control animals.

\section{INTRODUCTION}

Campylobacter jejuni is a common aetiological agent in traveller's diarrhoea. According to Finnish [1] and Swedish studies [2,3], in approximately $70 \%$ of reported cases the illness was acquired during travel outside the Nordic countries. The severity of the clinical symptoms varied, but most cases recovered spontaneously and no antimicrobial treatment was needed. Prophylactic administration of some antimicrobial agents for the prevention of diarrhoea is rather common. In the 1970s, after the confirmation of the role of ETEC (enterotoxigenic Escherichia coli) as one of the major aetiological agents in traveller's diarrhoea, antimicrobial prophylaxis was directed more particularly to this organism [4]. One group of the drugs widely used for the prevention of diarrhoea is that of the different bismuth salts, including bismuth subnitrate, bismuth subgallate, and bismuth subsalicylate (BSS). In one study BSS reduced the occurrence of traveller's diarrhoea by $62 \%$ when $240 \mathrm{ml}(17.5 \mathrm{mg} / \mathrm{ml} \mathrm{BSS})$ of the liquid formula was taken by mouth daily by US students in Mexico [56]. In another study, when the daily dose of bismuth subsalicylate was either 1.05 or $2.1 \mathrm{~g}$ on a twice-daily regimen, the diarrhoeal incidence was reduced by 35 to $41 \%$ [6]. In the studies mentioned above, campylobacters were not included in the microbiological diagnostic tests. The in vitro sensitivity of $C$. jejuni to bismuth compounds is not known.

In the present study, the efficacy of prophylactic or therapeutic dosages of bismuth subsalicyate in preventing the growth and colonization of C.jejuni in the intestinal tract of infant mice was investigated. The MIC value of bismuth subsalicylate to C. jejuni was also determined. 


\section{MATERIALS AND METHODS}

Bacterial strains. The five $C$. jejuni strains used in the colonization studies were $\mathrm{KH}$ and 12650, isolated from patients with diarrhoea; B 6 and B 42 , isolated from chickens; and L 69 isolated from a sheep. The strains were chosen because they were known to colonize the intestines of infant mice. These and 5 additional strains isolated from humans ( 2 strains), cattle ( 1 strain), and chicken ( 2 strains) were tested for in vitro sensitivity to bismuth subsalicylate. Before their use in the present study, the strains had been stored at $-70^{\circ} \mathrm{C}$ in Brucella FBP broth (Oxoid Ltd, UK).

Sensitivity testing. Bismuth subsalicylate (Orion Pharmaceuticals, Espoo, Finland) was first dissolved in $0.1 \mathrm{M}-\mathrm{HCl}$. After $5 \mathrm{~min}$ at ambient temperature, the $\mathrm{pH}$-value was adjusted to $7 \cdot 0$ with $1 \mathrm{M}-\mathrm{NaOH}$. Serially diluted concentrations of BSS were then added to Brucella blood agar and Brucella broth with FPB supplement $\left(\mathrm{FeSO}_{4} \cdot 7 \mathrm{H}_{2} \mathrm{O}\right.$, sodium pyruvate, sodium metabisulphite, each at concentration of $0.025 \%)$. These were inoculated with $5 \mu \mathrm{l}$ of a $24 \mathrm{~h}$ culture $\left(37^{\circ} \mathrm{C}\right)$ of campylobacters in Brucella FBP broth and the growth of bacteria was assessed after $48 \mathrm{~h}$ incubation at $37^{\circ} \mathrm{C}$.

Preparation of the challenge dose. The strains were grown in Brucella broth with $5 \%$ sterile citrated calf blood at $37{ }^{\circ} \mathrm{C}$ for $24-30 \mathrm{~h}$. The culture was diluted tenfold in $0.1 \%$ peptone water and the number of colony forming units (c.f.u.) of the inoculum was determined by spreading $0.1 \mathrm{ml}$ of appropriate dilutions on duplicate Brucella blood agar plates. The inoculum size used was $10^{4}-10^{5}$ c.f.u. per animal. All incubations of broth or plate cultures were made microaerophilically.

Bismuth subsalicylate (BSS). BSS (Orion Pharmaceuticals, Espoo, Finland) is highly insoluble in water. Therefore a milky suspension of BSS in water was prepared each time for the treatment of animals.

Treatment of animals. The experimental animals used were 4 to 9 -day-old infant mice. The adult females and males (NMRI; Orion Pharmaceuticals, Espoo, Finland) were mated and the infants were delivered to individually caged dams.

Three different treatment regimens were used : pre-treatment ; post-treatment; continuous treatment ('prophylaxis'). The protocols are shown in Table 1. The bacteria and BSS were inoculated intragastrically, $0.1 \mathrm{ml}$ each, using a $1.0 \mathrm{ml}$ tuberculin syringe fitted with a blunted 21 -gauge needle. The mice were killed by $\mathrm{CO}_{2}$ asphyxiation. Control animals were inoculated with the bacteria and sampled in the same way but did not receive BSS treatment.

Testing of efficacy. The growth of $C$.jejuni was tested by counting the c.f.u.s of campylobacters either from the whole intestine or separately from the small and large intestine. The intestine was homogenized in $9 \cdot 0 \mathrm{ml} 0.1 \%$ peptone water with a Colworth Stomacher Lab Blender (Tekmar; Cincinnati, OH). The homogenates were serially diluted in $0.1 \%$ peptone water; and $0.1 \mathrm{ml}$ of appropriate dilutions were spread on duplicate Blaser-Wang medium plates [7]. Similarly, the c.f.u.s of the challenge doses were counted on Brucella blood agar plates. After a $48 \mathrm{~h}$ incubation at $37^{\circ} \mathrm{C}$, the campylobacter colonies were counted. 
Table 1. Bismuth subsalicylate (BSS) treatment regimens in mice challenged with $10^{4}-10^{5}$ c.f.u. Campylobacter jejuni

\begin{tabular}{|c|c|c|c|c|c|}
\hline & & & $y$ of experim & & \\
\hline & 1 & 3 & 4 & 5 & 6 \\
\hline $\begin{array}{l}\text { Pre-challenge } \\
\text { treatment }\end{array}$ & $\begin{array}{c}\text { BSS } 2000 \mu \\
\text { daily }\end{array}$ & Challenge & $\begin{array}{l}\text { Killed and } \\
\text { tested }\end{array}$ & & \\
\hline $\begin{array}{l}\text { Post-challenge } \\
\text { treatment }\end{array}$ & Challenge & $\begin{array}{l}\text { BSS } 300 \mu \mathrm{g} \text { daily } \\
\text { two divided doses }\end{array}$ & & $\begin{array}{l}\text { Killed and } \\
\text { tested }\end{array}$ & \\
\hline $\begin{array}{l}\text { Continuous } \\
\text { treatment } \\
\text { ('prophylaxis') }\end{array}$ & BSS $2000 \mu \mathrm{g}$ & $\begin{array}{l}\text { Challenge } \\
300 \mu \mathrm{g} \text { daily in }\end{array}$ & wo divid & & d ana \\
\hline
\end{tabular}

\section{RESULTS}

Sensitivity of $\mathrm{C}$. jejuni to bismuth subsalicylate. The sensitivity $\left(\mathrm{MIC}_{90}\right)$ of $10 \mathrm{C}$. jejuni strains, including the strains used in the mice experiments, as tested either by the broth or agar dilution methods, was $900 \mu \mathrm{g}$ per $\mathrm{ml}$ (range 450-900 $\mu \mathrm{g} / \mathrm{ml}$ ).

Treatment experiments. None of the mice in any of the test or control groups showed signs of illness. The only visible sign, which was always seen in treated animals, was the dark greenish colour of the contents of the large intestine.

Pre-challenge treatment. The effects of 2 days of pre-treatment with BSS on the growth of $C$. jejuni in the intestine of infant mice are presented in Table 2. BSS administered to mice inhibited the growth of campylobacters. The difference of the means of c.f.u.s between control and treatment groups was significant $(P<$ $0 \cdot 001)$. The sensitivity of the method was $\log 2$ c.f.u per specimen. However, if the animals treated with BSS were killed 1 week after the bacterial inoculation, no difference in the counts $\left(10^{5}-10^{6}\right)$ between the two groups was found indicating that the effect of prophylactic treatment is restricted to the treatment period.

Post-challenge treatment. Table 3 presents the effect of BSS used as a therapeutic agent. With the lower daily dose of $300 \mu \mathrm{g}$ per animal for 3 days after the campylobacter challenge, the growth of the organism was not inhibited $(P<0.05)$. Only one strain, KH, was tested using both low and high doses of BSS. The high dose was apparently effective in inhibition of the growth of $C$.jejuni. In the high dosage regimen, in 6 of the 12 animals tested, campylobacters were undetectable at the level of the sensitivity of the method. The results, however, are not directly comparable because of different challenge doses.

Continuous pre-and post-challenge treatment. Treating the animals for 2 days before and 3 days after the bacterial challenge caused a statistically significant prevention of the growth of $C$.jejuni. With the dose of $2000 \mu \mathrm{g}$ per animal per day, the counts of campylobacters were under the detection level of $\log 2$ in all (17) treated animals (Table 4). Further, the low dose of $300 \mu \mathrm{g}$ per animal was also effective in prevention of the growth of $C$. jejuni. In the experiments with strains $\mathrm{KH}, \mathrm{B} \mathrm{42}$, and 9000 , the counts of campylobacters were analysed separately for the small and large intestine. The growth of campylobacters was inhibited both in the small and large intestine. When, however, the counts of campylobacters were 
Table 2. Effect of prophylactic treatment with bismuth subsalicylate* on the growth of $\mathrm{C}$. jejuni in the intestine of infant mice

\begin{tabular}{lcc} 
Bacterial & Bacterial counts (log c.f.u) per intestine \\
\cline { 2 - 3 } strain & Control animals & Treated animals \\
KH & $5 \cdot 18 \pm 1 \cdot 07(5) \dagger$ & $2 \cdot 41 \pm 1 \cdot 2(4)$ \\
L69 & $4 \cdot 75 \pm 0 \cdot 22(8)$ & $2 \cdot 55 \pm 0.57(11)$ \\
12650 & $4 \cdot 60 \pm 0 \cdot 60(5)$ & $2 \cdot 93 \pm 0 \cdot 81(14)$ \\
B42 & $4.5 \pm 0 \cdot 45(4)$ & $<2 \cdot 0 \ddagger(4)$
\end{tabular}

* Daily doses (2000 $\mu \mathrm{g}$ per animal) for 2 days before the bacterial challenge $\left(10^{4}-10^{5}\right.$ c.f.u. per animal). The animals were killed $24 \mathrm{~h}$ after the challenge.

$\dagger$ Number of animals given in parentheses.

$\ddagger$ Sensitivity of the detection method was $\log 2 \cdot 0$.

Table 3. Therapeutic use of bismuth subsalicylate (BSS) for prevention of the growth of $\mathrm{C}$. jejuni in the intestine of infant mice

\begin{tabular}{|c|c|c|c|}
\hline \multirow{2}{*}{$\begin{array}{l}\text { Bacterial strain/ } \\
\text { challenge dose } \\
\text { (c.f.u. per animal) }\end{array}$} & \multirow{2}{*}{$\begin{array}{l}\text { Daily dose of } \\
\text { BSS per animal } \\
(\mu \mathrm{g})^{*}\end{array}$} & \multicolumn{2}{|c|}{ Bacterial counts (log c.f.u. \pm s.D.) } \\
\hline & & Control animals & Treated animals \\
\hline $9000 / 7 \times 10^{5}$ & 300 & $7 \cdot 0 \pm 0 \cdot 19(3) \dagger$ & $3 \cdot 13 \pm 1 \cdot 45(6)$ \\
\hline $\mathrm{B} 42 / 2 \times 10^{6}$ & 300 & $587 \pm 0.10(2)$ & $5 \cdot 84 \pm 0.25(5)$ \\
\hline $\mathrm{KH} / 1 \times 10^{6}$ & 300 & $5 \cdot 89 \pm 0 \cdot 09(2)$ & $4 \cdot 36 \pm 0 \cdot 38(7)$ \\
\hline $\mathrm{KH} / 1 \times 10^{4}$ & 2000 & $5 \cdot 06 \pm 0.45(3)$ & $<2 \cdot 0-2 \cdot 47(12)$ \\
\hline
\end{tabular}

* For 3 days following the bacterial challenge. The animals were killed $24 \mathrm{~h}$ after the last dose.

$\dagger$ Number of animals given in parentheses.

analysed 1 week after the last dose of BSS, they were similar for both the treated and control animals, approximately $10^{5}-10^{6}$ per animal.

\section{DISCUSSION}

On the basis of in vitro studies of the activity of bismuth subsalicylate against ten C. jejuni strains in the present study, the organism does not appear to be very susceptible to the agent. Two strains were inhibited with a concentration of $450 \mu \mathrm{g} / \mathrm{ml}$ and eight strains with a concentration of $900 \mu \mathrm{g} / \mathrm{ml}$. Recently Cornick and colleagues [8], using an agar dilution method, tested the activity of BSS against a broad range of intestinal pathogens and commensals (for a total of 155 bacterial strains). No $C$. jejuni strains were included in that study, however. According to the results of Cornick and colleagues [8], the $\mathrm{MIC}_{90} \mathrm{~s}$ of ETEC, salmonella, and Clostridium difficile were 4096,2048 , and $128 \mu \mathrm{g} / \mathrm{ml}$, respectively. C. difficile was the most sensitive of the strains studied. On the other hand, Helicobacter pylori, a campylobacter-like organism harbouring in the gastric epithelium of humans, is very susceptible to BSS, the range of MICs being $2-32 \mu \mathrm{g} / \mathrm{ml}$ [9]. Various bismuth salts have been used successfully in clinical trials for the eradication of $H$. pylori from the gastric epithelium [10]. Based on the 





above results, C. jejuni seems in vitro to be more susceptible than ETEC, but less susceptible than $H$. pylori, to the activity of BSS. However, the results of different antimicrobial sensitivity studies cannot be directly compared, e.g. due to the poor solubility of BSS. The mechanism of the antimicrobial activity of bismuth salts against bacteria is not well understood. In the in vitro studies, a focal accumulation of particulate bismuth complex occurred under the cell wall, but no morphological changes were detected in H. pylori [11]. On the other hand, in the in vivo studies ultrastructural changes were seen in $H$. pylori in the endoscopic biopsies after treatment of patients with bismuth salts [10]. No results for other organisms were available. It is possible, however, that BSS acts in a non-specific way, preventing bacterial cell attachment to mucus or to specific receptors. Lee and co-workers [12] showed that in the mouse, campylobacters are mucus-colonizers, and do not adhere to the epithelial cells. Thus they are accessible to drugs such as bismuth compounds which are not absorbed but act locally on mucus surfaces. BSS was not shown to cause any significant changes in the total counts of intestinal flora or in the counts of specific groups of enteric organisms [13]. More research is needed to elucidate the antibacterial mechanism of BSS.

In the present study, the in vivo activity of BSS against $C$. jejuni was studied using infant mice challenged with $C$. jejuni in three different treatment regimens. The results provided some evidence of the in vivo activity of the agent. The BSS treatment was considered to be effective if the counts in treated animals were at least two log units lower than in control animals. This method has been used in the evaluation of the efficacy of vaccination in protection against colonization of $C$. jejuni in infant mice [14]. The statistical evaluation of the results confirmed the efficacy of the dosage regimens when BSS was either given as a daily pre-challenge or as a combined daily pre- and post-challenge dosage regimen. The therapeutic administration of BSS in low and high doses had a proportional effect on preventing the growth of $C$.jejuni. If the organism has already colonized, higher doses are probably needed for its eradication. In the third regimen, which represents the more typical dosage regimen used in the prevention of traveller's diarrhoea, both low and high doses prevented the growth of $C$. jejuni. These results indicate that the role of BSS has a prophylactic rather than therapeutic effect.

The infant mice model has been extensively used, e.g. in colonization $[15,16]$, pathogenesis [17], and immunity, [14,18] studies of campylobacter infection. These studies have shown that the animals are colonized from stomach to colon, and that colonization lasts at least for 2 weeks. The highest numbers of bacteria are found in the caecum and colon. In the present study as well, the highest counts of campylobacters, ranging from $10^{5}$ to $10^{7}$, were in the distal part of the intestine in control animals. The growth inhibition of campylobacters was effective in both the proximal and distal part of the intestine. In human infection the distribution of campylobacters in the intestine is not known, but the infection appears most commonly to involve the terminal ileum and colon [19].

BSS is not absorbable, and its antimicrobial effect was shown to last only for the period of treatment. One week after the last dose, there were no differences in the counts between the treated and control animals. Similarly, BSS treatment effectively removes $H$. pylori from the gastric mucosal surface, but relapses are 
frequent after the cessation of treatment [10]. The consequence of the above results for the use of BSS as a preventive treatment for traveller's diarrhoea caused by $C$. jejuni is that BSS should be continued for some days after return.

BSS has been shown to prevent traveller's diarrhoea by decreasing the occurrence of diarrhoeal symptoms as well as by acting directly on the causative agents. In studies in which the enteropathogens were investigated, the stool specimens of people treated with BSS were less commonly positive for shigella, salmonella or enteropathogenic $E$. coli than were the stool samples of the placebo group $[5,6]$. In these studies, however, campylobacter examination was not included. The present in vitro sensitivity studies, as well as the in vivo studies with infant mice, indicate that BSS might be effective in the prevention of traveller's diarrhoea caused by C. jejuni.

\section{REFERENCES}

1. Pitkänen T. Traveler's diarrhea caused by Campylobacter jejuni. Ann Clin Res 1982; 14: 111-13.

2. Svedhem Å, Kaiser B. Campylobacter fetus subspecies jejuni: a common cause of diarrhea in Sweden. J Infect Dis $1980 ; 142: 353-59$

3. Walder M. Epidemiology of Campylobacter enteritis. Scand J Infect Dis $1982 ; 14: 27-33$.

4. Gorbach, SL, Kean BH, Evans DG, et al. Traveler's diarrhea and toxigenic Escherichia coli. N Eng J Med 1975; 292: 933-6.

5. DuPont HI, Sullivan P, Evans GD, et al. Prevention of traveler's diarrhea. J Am Med Ass $1980 ; 243: 237-41$

6. Steffen R, DuPont HL, Heusser R, Helminger A, Witassek F, Manhart MD, Schár M Prevention of traveler's diarrhea by the tablet form of bismuth subsalicylate. Antimicrobial Agents Chemother $1986 ; 29: 625-7$.

7. Blaser MJ. Berkowitz ID, LaForce FM, Cravens J, Reller LB, Wang W-LL. Campylobacter enteritis: clinical and epidemiologic features. Ann Intern Med 1979; 91: 179-85.

8. Cornick MA. Silva M. Gorbach SL. In vitro activity of bismuth subsalicylate. In: Abstracts of the Annual Meeting of the American Society of Microbiology. Miami: American Society of Microbiology, 1988: 7 .

9. McNulty CAM, Dent J, Wise R. Susceptibility of clinical isolates of Campylobacter pyloridis to 11 antimicrobial agents In: Pearson AD, Skirrow MB, Lior H, Rowe B., eds. Campylobacter III. Proceedings of the Third International Workshop on Campylobacter Infections, Ottawa, 7-10 July 1985. London: Public Health Laboratory Service, 1985: $169-70$.

10. Marshall BJ, Warren JR, Blincow ED, et al. Prospective double-blind trial of duodenal ulcer relapse after eradication of Campylobacter pylori. Lancet 1988; ii: 1437-42.

11. Armstrong JA, Wee SH, Goodwin CS, Wilson DH. Response of Campylobacter pyloridis to antibiotics, bismuth and an acid-reducing agent in vitro-an ultrastructural study. J. Med Microbiol $1987 ; 24: 343-50$.

12. Lee A, O'Rourke JL, Barrington PJ, Trust TJ. Mucus colonization as a determinant of pathogenicity in intestinal infection by Campylobacter jejuni: a mouse cecal model. Infect Immun $1986 ; 51: 536-46$.

13. Cornick MA, Silva M, Gorbach SL. Effect of bismuth subsalicylate on normal bowel flora. In: Abstracts of the Annual Meeting of the American Society of Microbiology. Miami: American Society of Microbiology, 1988: 7 .

14. Abimiku AG, Dolby JM, Borriello SP. Comparison of different vaccines and induced immune response against Campylobacter jejuni colonization in the infant mouse. Epidemiol Infect $1989 ; 102: 271-80$.

15. Field LH, Lnderwood JI, Pope LM. Berry LJ. Intestinal colonization of neonatal animals by Campylobacter fetus subsp. jejuni. Infect Immun $1981 ; 33$ : 884-92.

16. Hänninen ML. Effect of endotoxin on the colonisation of Campylobacter jejuni in infant mice. J Med Microbiol $1989 ; 30$ : $199-206$. 
17. Kazmi SU, Roberson BS, Stern NJ. Animal-passed, virulence enhanced Campylobacter jejuni causes enteritis in neonatal mice. Curr Microbiol 1984; 11: 159-64.

18. Dolby JM, Newell DG. The protection of infant mice from colonization with Campylobacter jejuni by vaccination of the dams. J Hyg $1986 ; 96$ : 143-51.

19. Walker RI, Caldwell MB, Lee CI, Guerry P, Trust TJ, Ruiz-Palacios M. Pathophysiology of Campylobacter enteritis. Microbiol Rev 1986; 50 : $81-94$. 